\title{
Application of Circulating Tumor Cells in Peripheral Blood in Judging the Prognosis of Patients with Renal Cancer and Related Indexes of Blood Coagulation
}

\author{
Dianbin Song ${ }^{1}$, Zhiyong Wang ${ }^{1}$, Xiuming Li ${ }^{1}$, Jingjing Zhang ${ }^{2}$, Qiang Chi' ${ }^{1}$, Hui Xu${ }^{1}$, \\ Hongyang $\mathrm{Li}^{1}$, Ying Liu ${ }^{1}$
}

${ }^{1}$ Department of Urology, Affiliated Hospital of Chengde Medical College, Chengde, China

${ }^{2}$ Department of Oncology, Affiliated Hospital of Chengde Medical College, Chengde, China

Email: *songdianbin123@163.com

How to cite this paper: Song, D.B., Wang, Z.Y., Li, X.M., Zhang, J.J., Chi, Q., Xu, H., Li, H.Y. and Liu, Y. (2022) Application of Circulating Tumor Cells in Peripheral Blood in Judging the Prognosis of Patients with Renal Cancer and Related Indexes of Blood Coagulation. Open Journal of Urology, 12, 1-6. https://doi.org/10.4236/oju.2022.121001

Received: December 15, 2021

Accepted: January 8, 2022

Published: January 11, 2022

Copyright $\odot 2022$ by author(s) and Scientific Research Publishing Inc. This work is licensed under the Creative Commons Attribution International License (CC BY 4.0).

http://creativecommons.org/licenses/by/4.0/

\begin{abstract}
Objective: To investigate the value of the number of circulating tumor cells (CTC) in peripheral blood in the prognosis and coagulation-related indicators of patients with renal cancer. Methods: 65 patients with renal cell carcinoma (RCC) confirmed pathologically were divided into CTC positive group and CTC negative group according to the CTC count (5 pcs/3.5 ml). Compare the age, gender, tumor location, TNM (clinical stage), pathological grade, tissue type, lymph node metastasis, distant metastasis, prognosis and prothrombin time (PT), fibrinogen (FIB), partial coagulation of the two groups of patients The correlation between the results of zymogen time (APTT) and D-dimer (DD) and the number of CTC. Results: There were significant differences in TNM, lymph node metastasis, and distant metastasis between the two groups $(\mathrm{P}<0.05)$. The number of CTC in patients was correlated with FIB and D-D levels $(\mathrm{P}<0.05)$. Conclusion: The number of CTC in patients with renal cell carcinoma is correlated with some clinical phenotypes (TNM, lymph node metastasis, distant metastasis) and some coagulation indexes (FIB, D-D), and can jointly predict the prognosis of renal cancer.
\end{abstract}

\section{Keywords}

Peripheral Blood Circulating Tumor Cells, Renal Cancer, Clinical Phenotype, Coagulation Index

\section{Introduction}

Renal cell carcinoma (RCC) accounts for about $2 \%$ - $3 \%$ of adult malignant tumors, and it is increasing at a rate of more than 200,000 new cases and more 
than 100,000 deaths worldwide each year. Among RCC patients, 30\% of patients had metastasis when the tumor was discovered, and it was also found that the postoperative recurrence rate of patients with localized RCC reached about 30\% [1]. Therefore, the current important problem facing RCC is how to prevent tumor recurrence and metastasis.

Circulating tumor cells (CTC) are a type of tumor cells in the circulatory system. Previous studies have shown that, compared with the primary tumor, CTC has greater potential in predicting tumor recurrence, metastasis and prognosis [2]. In recent years, the value of CTC as a malignant biomarker and prognostic evaluation index has received more and more attention [3]. At present, CTC quantification has been used to assess tumor staging [4] [5]. The updated knowledge indicates that CTC plays a potentially key role in the prognosis or diagnosis of RCC. In this study, the number of CTCs in peripheral blood of patients with renal cancer was detected, combined with various clinical phenotypes and coagulation-related test indicators, to provide clinical data support for the prognosis of CTC-based RCC.

\section{Materials and Methods}

\subsection{General Information}

This study conducted a retrospective study of 65 RCC patients who visited the Department of Urology from May 2018 to February 2020 in the Affiliated Hospital of Chengde Medical College (hereinafter referred to as our hospital).

\subsection{Inclusion Criteria}

1) All patients were diagnosed pathologically, through hand gestures or renal tumor biopsy. 2) All patients have complete clinical data. 3) All patients signed an informed consent form.

\subsection{Exclusion Criteria}

1) Patients with other tumors; 2) Patients with blood system related diseases (including thrombotic diseases and drugs that affect blood coagulation); 3) $\mathrm{Pa}$ tients who cannot tolerate surgery or biopsy; 4) Within 1 week Patients undergoing dialysis and blood transfusion; 5) Patients participating in other clinical studies within one month; 6) Children, pregnant women, breastfeeding women, and mentally ill patients.

\subsection{Judgment Criteria}

The criteria for the positive grouping of patients with CTC are based on domestic and foreign literature [6], the criteria for the positive group is CTC $\geq 5 / 3.5$ $\mathrm{mL}$, and the negative group is CTC $<5 / 3.5 \mathrm{~mL}$.

\subsection{Detection Method}

The peripheral blood of 65 patients with renal cancer in our hospital was taken 
early in the morning to detect the number of CTCs. At the same time, the age, gender, tumor location, TNM (clinical stage), pathological grade, tissue type, and lymph node metastasis of the two groups were recorded. Distant metastasis, prognosis and the values of prothrombin time (PT), fibrinogen (FIB), partial prothrombin time (APTT) and D-dimer (DD).

\subsection{Statistics}

Use SPSS 22.0 to perform statistical analysis on the data. The measurement data are expressed as mean \pm standard deviation, which conforms to the t-test of homogeneity of variance and normal distribution. The comparison of count data adopts the chi-square test. $\mathrm{P}<0.05$ means the difference is statistically significant.

\section{Results}

1) There was no difference in general information between the CTC-positive group and the CTC-negative group (see Table 1).

2) The two groups of patients have differences in TNM, lymph node metastasis, and distant metastasis $(\mathrm{P}<0.05)$ (see Table 2).

3) CTC count is correlated with some coagulation indexes in patients with renal cell carcinoma $(\mathrm{P}<0.05)$ (see Table 3$)$.

\section{Discussion}

At present, the early diagnosis of RCC is still an important factor affecting the prognosis, and the benefit of patients with advanced RCC is still limited [7]. CTC detection can detect the primary tumor earlier, reflect the metastasis of the primary tumor in time, and assist in judging the progress of the disease [8]. As a type of tumor cells free from the circulatory system, the number of CTC has been shown to be related to the prognosis of the tumor [9]. Related studies have found that CTC also plays a certain role in guiding tumor treatment [10]. It has also been confirmed as a tumor biomarker that can predict the outcome of

Table 1. Comparison of general information of patients.

\begin{tabular}{|c|c|c|c|c|c|c|}
\hline \multirow{2}{*}{ Group } & \multirow{2}{*}{$\begin{array}{l}\text { Number } \\
\text { of cases }\end{array}$} & \multicolumn{2}{|c|}{ Gender (example) } & \multirow{2}{*}{ age } & \multicolumn{2}{|c|}{ Onset location (case) } \\
\hline & & Female & male & & Left & Right \\
\hline CTC positive group & 33 & 15 & 18 & $54.9 \pm 1.2$ & 19 & 14 \\
\hline CTC negative group & 32 & 15 & 17 & $52.1 \pm 0.8$ & 17 & 15 \\
\hline$\chi^{2}$ value & & 0.406 & & & & \\
\hline t value & & & & -2.311 & & \\
\hline $\mathrm{P}$ value & & 0.273 & & 0.09 & & \\
\hline
\end{tabular}

Note: All $\mathrm{P}$ values are $>0.05$, the difference is not statistically significant. 
Table 2. Comparison of the clinical phenotypes of the two groups of patients.

\begin{tabular}{|c|c|c|c|c|}
\hline & $\begin{array}{l}\text { CTC positive } \\
\text { group }\end{array}$ & $\begin{array}{l}\text { CTC negative } \\
\text { group }\end{array}$ & statistics & $P$ value \\
\hline $\mathrm{TNM}(\mathrm{T} 1 / \geq \mathrm{T} 2)$ & $12 / 21$ & $25 / 7$ & $\mathrm{z}=4.105$ & $<0.0001$ \\
\hline Pathological grade $(\leq \mathrm{II} / \geq \mathrm{III})$ & $16 / 3$ & $9 / 1$ & $z=0.7569$ & 0.3615 \\
\hline $\begin{array}{l}\text { Tissue type (clear cell } \\
\text { carcinoma/papillary carcinoma) }\end{array}$ & $22 / 2$ & $14 / 1$ & $\mathrm{z}=0.274$ & 0.8083 \\
\hline $\begin{array}{l}\text { Lymph node metastasis } \\
\text { (positive/negative) }\end{array}$ & $11 / 20$ & $0 / 20$ & $\mathrm{z}=3.005$ & 0.0036 \\
\hline CTC & $11.25 \pm 0.9070$ & $1.950 \pm 0.3362$ & $t=9.415$ & $<0.0001$ \\
\hline Distant transfer (yes/no) & $15 / 15$ & $1 / 19$ & $\mathrm{z}=3.345$ & 0.0008 \\
\hline Prognosis (survival/death) & $25 / 4$ & $17 / 0$ & $\mathrm{z}=1.759$ & 0.073 \\
\hline
\end{tabular}

Table 3. The relationship between CTCs and PT, APTT, FIB, D-D in patients with renal cancer $(\mathrm{x} \pm \mathrm{s})$.

\begin{tabular}{cccccc}
\hline Group & $\begin{array}{c}\text { Number } \\
\text { of cases }\end{array}$ & PT (s) & APTT $(\mathrm{s})$ & FIB $(\mathrm{g} / \mathrm{L})$ & D-D (ug/L) \\
\hline $\begin{array}{c}\text { CTC } \\
\text { positive } \\
\text { group }\end{array}$ & 33 & $21.80 \pm 6.20$ & $33.50 \pm 1.50$ & $5.06 \pm 0.25$ & $316.10 \pm 22.50$ \\
$\begin{array}{c}\text { CTC } \\
\text { negative } \\
\text { group }\end{array}$ & 32 & $15.50 \pm 0.70$ & $29.80 \pm 1.20$ & $3.87 \pm 1.21$ & $232.20 \pm 13.10$ \\
$\begin{array}{c}Z \\
\text { v value }\end{array}$ & & 4.155 & 4.183 & 3.113 & 3.068 \\
P value & & 0.366 & 0.317 & 0.043 & 0.045 \\
\hline
\end{tabular}

treatment [11]. Although the survival and metastasis mechanism of CTC in peripheral blood has not been fully revealed, previous studies have confirmed that the mortality of most RCC patients is related to CTC-induced tumor metastasis [12]. In this study, we also found that there are significant differences in some clinical phenotypes of patients with different numbers of CTC renal cell carcinoma, such as TNM staging, lymph node metastasis, etc., indicating that CTC levels will affect the clinical phenotype of renal cell carcinoma patients, so we infer that, the number of CTC will also have a significant impact on the prognosis of renal cancer patients, and has the potential to predict the prognosis of RCC patients.

Previous studies have found that the occurrence and metastasis of tumor cells are related to the increase of D-D and FIB [13] [14]. The main reason is that $\mathrm{D}-\mathrm{D}$ is related to the occurrence of tumors, which can increase fibrinolytic response and help tumor cell colonization and aggregation. Second, when tumor metastasis or micrometastasis occurs, FIB in the body will increase, indicating that FIB is related to tumor metastasis. In this study, the D-D and FIB of the CTC positive group were significantly higher than those of the negative group, 
suggesting that patients in the CTC positive group are beneficial to tumor occurrence and metastasis. Therefore, observing the changes in CTC counts can reflect the changes in the body's environment and help determine whether the tumor has metastasized.

The number of CTCs in renal cancer patients combined with TNM staging, lymph node metastasis, distant metastasis and FIB, D-D values can assist renal cancer patients in judging their curative effect and prognosis, and provide clinical data support for patients with CTC-based RCC. This study is a single-center study with a limited amount of data. Future studies will further expand the sample size.

\section{Funded Project}

S \& T Program of Chengde (201904A025).

\section{Conflicts of Interest}

The authors declare no conflicts of interest regarding the publication of this paper.

\section{References}

[1] Brookman-May, S.D., May, M., et al. (2013) Time to Recurrence is a Significant Predictor of Cancer Spcific Survival after Recurrence in Patients with Recurrent Renal Cell Carcinoma-Results from a Comprehrnsive Multi-Centre Database (CORONA/ SATURN-Project). BJU International, 112, 909-916. https://doi.org/10.1111/bju.12246

[2] Zhao, W., Liu, Y., Jenkins, B.D., Cheng, R., Harris, B.N., Zhang, W., Xie, J., Murrow, J.R., Hodgson, J., Egan, M., et al. (2019) Tumor Antigen-Independent and Cell Size Variation-Inclusive Enrichment of Viable Circulating Tumor Cells. Lab Chip, 19, 1860-1876. https://doi.org/10.1039/C9LC00210C

[3] Plaks, V., Koopman, C.D. and Werb, Z. (2013) Cancer. Circulating Tumor Cells. Science, 341, 1186-1188. https://doi.org/10.1126/science.1235226

[4] Lorente, D., Olmos, D., Mateo, J., Dolling, D., Bianchini, D., Seed, G., Flohr, P., Crespo, M., Figueiredo, I., Miranda, S., et al. (2018) Circulating Tumour Cell Increase as a Biomarker of Disease Progression in Metastatic Castration-Resistant Prostate Cancer Patients with Low Baseline CTC Counts. Annals of Oncology, 29, 1554-1560. https://doi.org/10.1093/annonc/mdy172

[5] Xu, H.T., Miao, J., Liu, J.W., Zhang, L.G. and Zhang, Q.G. (2017) Prognostic Value of Circulating Tumor Cells in Esophageal Cancer. World Journal of Gastroenterology, 23, 1310-1318. https://doi.org/10.3748/wjg.v23.i7.1310

[6] Reid, A.H., Attard, G., Danila, D.C., et al. (2010) Significant and Sustained Antitumor Activity in Post-Docetaxel, Castrationresistant Prostate Cancer with the CYP17 Inhibitor Abiraterone Acetate. Journal of Clinical Oncology, 28, 1489-1495. https://doi.org/10.1200/JCO.2009.24.6819

[7] Rasmussen, F. (2013) Metastatic Renal Cell Cancer. Cancer Imaging, 13, 374-380. https://doi.org/10.1102/1470-7330.2013.9035

[8] Benezeder, T., Tiran, V., Treitler, A.A.N., et al. (2017) Mulrigene Methylation Analysis of Enriched Circulating Tumor Cells Associates with Poor Progresion-Free Sur- 
vival in Metastatic Breast Cancer Patients. Oncotarget, 8, 92483-92496.

https://doi.org/10.18632/oncotarget.21426

[9] Wallwiener, M., Riethdorf, S., Hartkopf, A.D., Modugno, C., Nees, J., Madhavan, D., Sprick, M.R., Schott, S., Domschke, C., Baccelli, I., et al. (2014) Serial Enumeration of Circulating Tumor Cells Predicts Treatment Response and Prognosis in Metastatic Breast Cancer: A Prospective Study in 393 Patients. BMC Cancer, 14, Article No. 512. https://doi.org/10.1186/1471-2407-14-512

[10] Cristofanilli, M., Pierga, J.Y., Reuben, J., Rademaker, A., Davis, A.A., Peeters, D.J., Fehm, T., Nolé, F., Gisbert-Criado, R., Mavroudis, D., et al. (2019) The Clinical Use of Circulating Tumor Cells (CTCs) Enumeration for Staging of Metastatic Breast Cancer (MBC): International Expert Consensus Paper. Critical Reviews in Oncology/Hematology, 134, 39-45. https://doi.org/10.1016/j.critrevonc.2018.12.004

[11] Smerage, J.B., Barlow, W.E., Hortobagyi, G.N., Winer, E.P., Leyland-Jones, B., Srkalovic, G., Tejwani, S., Schott, A.F., O’Rourke, M.A., Lew, D.L., et al. (2014) Circulating Tumor Cells and Response to Chemotherapy in Metastatic Breast Cancer: SWOG S0500. Journal of Clinical Oncology, 32, 3483-3489.

https://doi.org/10.1200/JCO.2014.56.2561

[12] Wen, L., Guo, L., Zhang, W., Li, Y., Jiang, W., Di, X., Ma, J., Feng, L., Zhang, K. and Shou, J. (2019) Cooperation between the Inflammation and Coagulation Systems Promotes the Survival of Circulating Tumor Cells in Renal Cell Carcinoma Patients. Frontiers in Oncology, 9, Article No. 504. https://doi.org/10.3389/fonc.2019.00504

[13] (2011) Correlation between Coagulation Function, Tumor Stage and Metastasis in Patients with Renal Cell Carcinoma: A Retrospective Study. Chinese Medical Journal: English Edition, 124, 1205-1208.

[14] Tang, Y. and Tang, H.Y. (2017) Study on the Correlation between Circulating Tumor Cells in Peripheral Blood and Clinical Features in Elderly Patients with Prostate Cancer. Chinese Journal of Hemorheology, 27, 55-57. 